\title{
Natural selection and geographical variation in a known sex-linked gene of the Common Lizard in Europe. Implications for chromosomal evolution
}

\author{
Sebastiano Salvidio*ף \\ Georges Pasteur* \\ Benoît Heulin† \\ Wolfgang Böhme \\ Larissa Kupriyanova§ and \\ Claude Guillaume\|
}

\author{
* Laboratoire de Génétique Ecologique, EPHE, \\ place Eugène-Bataillon, 34060 Montpellier, France. \\ $\uparrow$ Station Biologique de Paimpont, 35380 Plélan, \\ France. \\ $\ddagger$ Zoologisches Forschungsinstitut, \\ Adenauerallee 150-164, 5300 Bonn 1, FR Germany. \\ $\S$ Zoological Institute, Academy of Sciences, \\ Leningrad 199164, USSR. \\ || Laboratoire de Biogéographie et Ecologie des \\ Vertébrés, EPHE, place Eugène-Bataillon, \\ 34060 Montpellier, France. \\ I Istituto di Zoologia della Università, Via Balbi 5, \\ 16126 Genova, Italy.
}

The gene coding for mannose phosphate isomerase (MPI) has been found to be sex-linked in Common Lizard (Lacerta vivipara) samples from Russia to France. Both sex chromosomes can express one or two codominant alleles. The results are in agreement with the $Z_{1} Z_{2} W$ heteromorphic karyotype described in $L$. vivipara populations from central France. Allozyme frequencies can strongly vary between regions; in the Austrian population sampled, an allele that is rare or absent elsewhere has been fixed on chromosome $W$. The possibility is raised that habitat selection involving MPI allozymes will be demonstrated with suitable sampling, while the existence of endocyclic selection has been substantiated. The data suggest that the $Z_{1} Z_{2} W$ sex determination system is older than implied by the literature and possibly fixed in the whole species, but it is concluded that another sex-linked gene than $M P I$ has been instrumental in fixing the translocation involved.

\section{INTRODUCTION}

The Common Lizard, Lacerta vivipara (=Zootoca vivipara), extends over the Eurasiatic continent, often with population densities of $10^{2}$ to $10^{3}$ per ha, from Spain to beyond the polar circle to Kamchatka. Despite this vastness, $L$. vivipara is remarkably uniform morphologically and ecologically, mostly living in meadows, bogs, herby glades and the like, wandering little out of damp flat land. This suggests active, levelling genetic exchanges between populations throughout the range. At the karyotype level, however, there exist two very distinct kinds of populations according to the literature. From chromosomal studies, some populations from Switzerland and the Netherlands (van Brink, 1959) and Russia (Orlova and Orlov, 1969) have been assessed to be homomorphic, while others, from France's Massif Central, have been shown to have a visible $\mathrm{Z}_{1} \mathrm{Z}_{2} \mathrm{~W}$ heteromorphic sex-determination system (Chevalier et al., 1979).

In populations from the same area of France, Goux and Pasteur (1986) found that allozyme frequencies at the polymorphic mannose-phosphate-isomerase (MPI) locus can only be intelligibly accounted for if they are sex-linked in a female-heterogametic ( $Z W)$ system. Of the two recognized alleles, $M P I^{100}$ was on a $Z$ chromosome pair, and $M P I^{120}$ was on both this $\mathrm{Z}$ pair and the $\mathrm{W}$ chromosome. These data were in good accordance with Chevalier et al.'s (1979) findings; in addition, all evidence pointed toward a recent establishment of the observed linkage, relative to what is known about similar sex linkages in mammals and birds.

The observation of both homomorphic and heteromorphic populations in L. vivipara raised the exciting possibility of studying incipient 
chromosomal sex determination. This prompted us to explore the MPI polymorphism over a wider range, with the hope of increasing the understanding of early sex chromosome evolution. This paper reports the results of our investigations in populations from five regions of Europe, the western part of the $L$. vivipara range. Thanks to technical improvements, three allozymes, rather than two, can now be routinely distinguished through electrophoresis. While evidence of non-heterosomal sex determination has not been observed in the sampled populations, gene frequencies in some suggest that MPI alleles are sensitive to selection and thus ecophysiologically important, and definite inter-region qualitative differences in MPI allele distribution have been found.

\section{MATERIALS AND METHODS}

In addition to further specimens from the Massif Central which have been electrophoretically analysed by one of us (S.S.), we have investigated the MPI locus in samples from Brittany (Paimpont vicinity, see Heulin, 1984), Westphalia (Kottenforst, near Bonn), Schleswig-Holstein (Kaltenhofer Moor near Kiel), southern Leningrad District ( $c a .100 \mathrm{~km}$ south of Leningrad), and the Lower Austria/Styria border (between Mariazell and Göstling at $15^{\circ} \mathrm{E}$ and $48^{\circ} \mathrm{N}$ ). In table 1 , the Paimpont and Massif Central's Lake of Charpal samples include subsamples from different habitats distant by a few hundred meters from one another, and other Massif Central samples combine local collections from stations separated by from 2-12 kilometers.

Liver homogenates were run through horizontal starch gel electrophoresis, using a 12.5 per cent starch concentration in TC 6.7 buffer. Running time was $6-7 \mathrm{~h}$ at $70 \mathrm{~mA}$. Long migration time and addition of from $0 \cdot 5-1 \mathrm{ml}$ of 1 per cent NADP to both gel and electrode buffers seem to have been the main improvements necessary to secure three distinct alleles rather than two. The two buffers and the staining are described in Pasteur et al. (1988b, pp. $85-86$ and p. 138 respectively). Since the new electromorph that this technique allows to distinguish displays intermediate migration between $M P I^{100}$ and $M P I^{120}$, we designate it $M P I^{110}$.

All specimens were collected during the warm season, as these lizards hibernate. In tables and text, "adults" are those lizards where sexual maturity had been reached or was to be reached within the season, and "young" are the remaining individuals. Genotypes of a non-collected begetter from Kaltenhofer Moor and another one from south Leningrad were inferred from progeny genotypes in gravid females.

\section{RESULTS}

Absolute genotype frequencies observed for the three detectable MPI alleles in every sample are given in table 1. Two homozygous genotypes are completely missing throughout, $M P I^{110 / 110}$ in the two sexes and $M P I^{100 / 100}$ in females. The most easterly (Russia) and westerly (France) samples are qualitatively comparable, with both 110 and 120 alleles, while the German and Austrian samples have strikingly fewer genotypes. (The southern Leningrad sample is too small to include every possible genotype, but comparisons between samples can be made with expected frequencies.)

\section{Sex linkage}

With the many empty cells in table 1 , it can be seen at a glance that in the samples investigated the MPI locus does not follow autosomal inheritance, suggesting sex linkage in all populations. In fact, all the data are interpretable following the Goux and Pasteur (1986) ZW hypothesis: allowing for statistical deviations due to sample sizes, actual genotype frequencies are as perfect a match as one can expect to genotype numbers as computed (table 1) from the estimated allele frequencies (table 2) when:

$M P I^{100}$ is assumed to exist only on a $\mathrm{Z}$ chromosome pair;

$M P I^{110}$ is assumed to exist only on the W chromosome;

$M P I^{120}$ is assumed to exist on both homologous chromosomes.

A cytogenetical study of the present samples is under way (V. Volobouev, in preparation).

\section{Selection}

It will be noted that a few 120/120 homozygotes are present among males. Insofar as the Paimpont sample is concerned, the Goux and Pasteur (1986) contention that absence of this genotype is more likely to result from sampling chance than lethality in homozygous males is vindicated. The absence of homozygous males for $M P I^{120}$ in the Massif Central general sample of 211 does not constitute a significant deviation from expected frequencies under the assumption of random mating within 


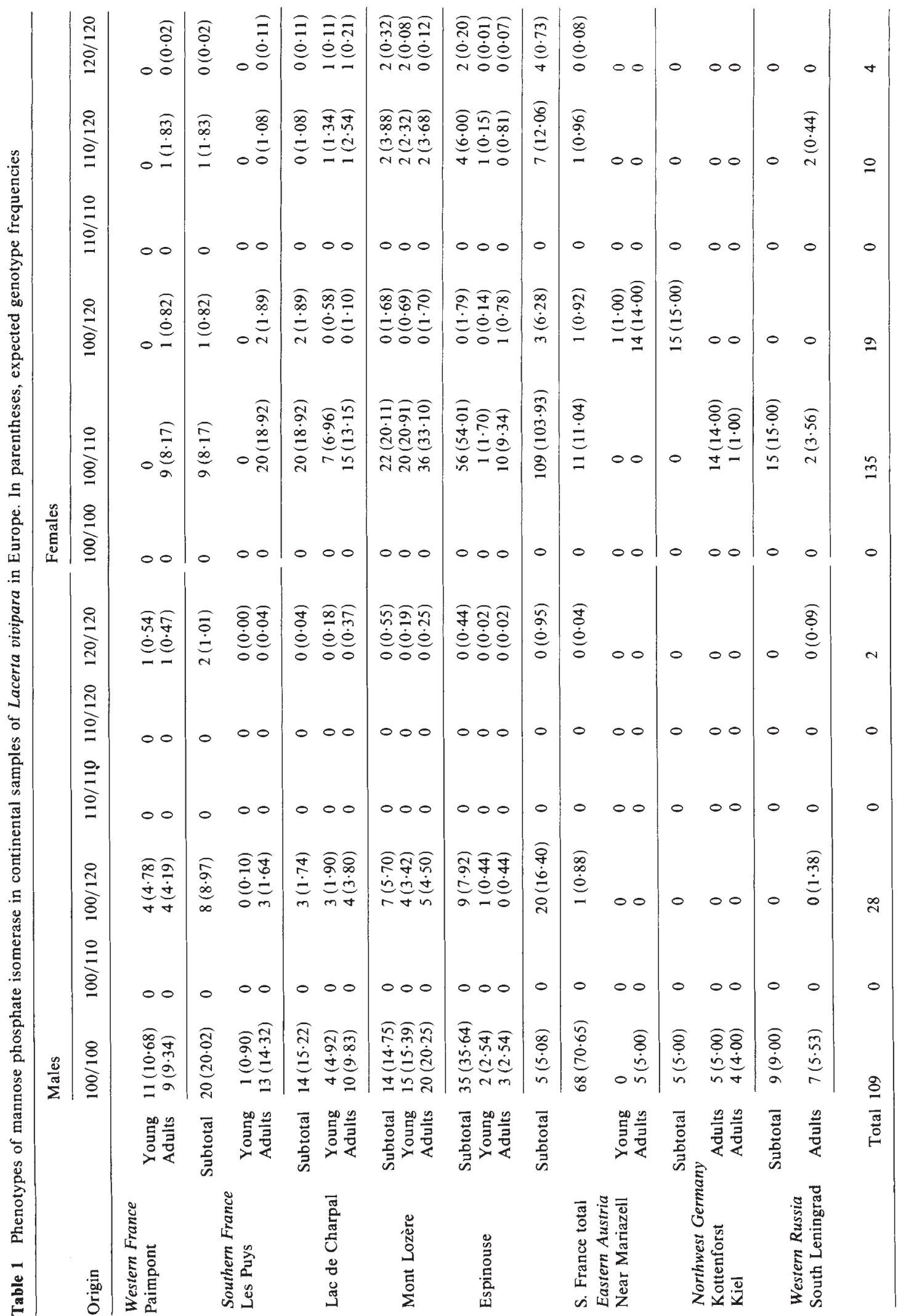


Table 2 Allele frequencies at the Common Lizard MPI locus, computed from table 1 data

\begin{tabular}{|c|c|c|c|c|c|c|}
\hline \multirow[b]{2}{*}{ Sample origin } & \multicolumn{3}{|c|}{$\mathrm{Z}$ chromosomes } & \multicolumn{3}{|c|}{ W chromosomes } \\
\hline & $M P I^{1000}$ & $M P I^{110}$ & $M P I^{120}$ & $M P I^{100}$ & $M P I^{110}$ & $M P I^{120}$ \\
\hline $\begin{array}{l}\text { Brittany } \\
\text { Paimpont }\end{array}$ & 0.82 & - & $0 \cdot 18$ & - & 0.91 & 0.09 \\
\hline $\begin{array}{l}\text { Massif Central } \\
\text { Les Puys } \\
\text { Lac de Charpal } \\
\text { Mont Lozère } \\
\text { Espinouse }\end{array}$ & $\begin{array}{l}0.95 \\
0.84 \\
0.90 \\
0.92\end{array}$ & $\begin{array}{l}- \\
\overline{-}\end{array}$ & $\begin{array}{l}0.05 \\
0 \cdot 16 \\
0 \cdot 10 \\
0.08\end{array}$ & $\begin{array}{l}- \\
- \\
-\end{array}$ & $\begin{array}{l}0.91 \\
0.92 \\
0.97 \\
0.92\end{array}$ & $\begin{array}{l}0.09 \\
0.08 \\
0.03 \\
0.08\end{array}$ \\
\hline Massif Central weighted mean & 0.90 & - & $0 \cdot 10$ & - & 0.94 & 0.06 \\
\hline $\begin{array}{l}\text { Northwestern Germany } \\
\text { Kottenforst } \\
\text { Kiel }\end{array}$ & $\begin{array}{l}1.00 \\
1.00\end{array}$ & - & - & - & $\begin{array}{l}1.00 \\
1.00\end{array}$ & - \\
\hline $\begin{array}{l}\text { Eastern Austria } \\
\text { Mariazell }\end{array}$ & 1.00 & - & - & - & - & $1 \cdot 00$ \\
\hline $\begin{array}{l}\text { Western Russia } \\
\text { Leningrad }\end{array}$ & 0.89 & - & $0 \cdot 11$ & - & $1 \cdot 00$ & - \\
\hline
\end{tabular}

the pool of Z-carried alleles. Therefore, the present data do not offer evidence of any normalizing selection. But they do suggest the existence of other forms of natural selection acting upon the MPI gene.

\section{Selection between neighbouring subpopulations}

In the Paimpont area (see Heulin, 1984), the Common Lizard population constitutes a continuous network between and, along lanes and ditches, across woodland lots inhospitable to the species. The spectrum of $L$. vivipara habitats there can be broken down into three classes: (1) moist meadows and heath, (2) the Paimpont Lake shore, and (3) wood edges and other fringe forest habitats with a more or less hygrophilous vegetation, such as thinnings, lane sides and ditch edges inside the woody parts.

The Paimpont sample is made of subsamples from four collecting places, any one of which was at less than $500 \mathrm{~m}$ from the nearest other one (fig. 1). These spots include the three kinds of habitats. However inadequate the sample may be with only 82 individual alleles, allozyme distribution suggests some corresponding diversification at the MPI locus (table 3): there clearly is no significant heterogeneity in the proportion of sex-limited $M P I^{110}$, but testing the microgeographic relation of $M P I^{100}$ and $M P I^{120}$ between the forest subsample and pooled samples A, B and C yields a $\chi_{\mathrm{c}}^{2}$ of $5 \cdot 8(P=0 \cdot 016)$. It follows that further investi- gation of these places would be worthwhile, in order to check about the possiblity of habitat selection acting upon MPI allozymes; knowing that each location is largely within the one-generation migration distance from the other (see Heulin, 1984), stochastic factors could hardly be involved. Collecting conditions, however, might somehow have introduced a bias in the present Paimpont sample.

In a more substantial composite sample (Mount Lozère, see table 1), where distances between collecting spots measured in kilometers and habitats belonged to class 1 above in all sampled biotopes, the MPI allele frequencies are similar throughout.

\section{Endocyclic selection}

A total of 211 ( 88 male and 123 female) Common Lizards have been collected from four different sites in southern France central mountains (Massif Central). Mount Lozère was the only site sampled twice: once in 1978 (20 males, 27 females) and once in 1986 ( 24 males, 35 females). In table 1 the data have been pooled, since genotype frequencies, within the two age classes of both males and females from the two temporal subsamples, did not show any significant deviation from a homogeneous distribution. Stable ratios of MPI allozymes have been maintained, in this population, at least over eight years. Such a period involves four to five $L$. vivipara generations, since Common Lizards inhabiting the Massif Central reach 

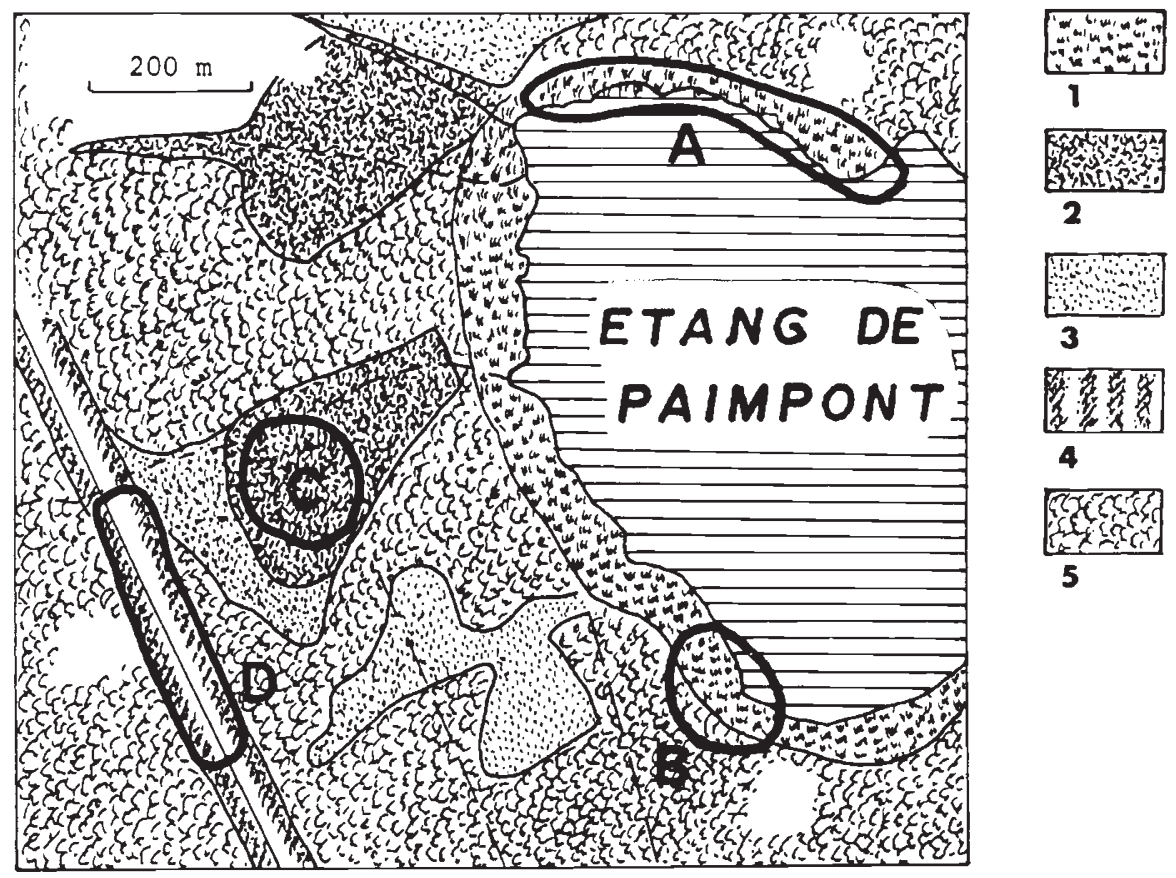

Figure 1 Collecting locations of Lacerta vivipara west of Paimpont, eastern Brittany. 1, bog; 2, peat; 3, heath; 4, heathy outskirts of woods; 5 , woods.

sexual maturity before their second winter (Pilorge, 1981).

Results of the present study are, to some extent, consistent with previous results by Goux and Pasteur (1986), who found "some indication for a mild selection favouring", in both sexes, "allozyme MPI ${ }^{100}$ against MPI ${ }^{120}$ during postnatal life ...". At that time, allele $M P I^{110}$ was not distinguished.

The present data show that, within male Massif Central samples, no differences in allele frequencies exist among age classes (table 1), whereas an unequal distribution of MPI electromorphs between adult and young females is present, with a concordant trend, in all populations (table 4). If all female samples are pooled, a significant deviation from homogeneity clearly appears: the proportion of the MPI ${ }^{120}$ allozyme is significantly higher in younger than in adult females in relation to both $\mathrm{MPI}^{100}\left(\chi_{\mathrm{c}}^{2}=7 \cdot 72, P<0.006\right)$ and $\mathrm{MPI}^{110}$ $\left(\chi_{\mathrm{c}}^{2}=6.37, P<0.012\right)$.

These findings are consistent with a selective pressure favouring the latter two allozymes in sexually mature $L$. vivipara females, as described by Goux and Pasteur (1986) for the two in aggregate. Under a constant selective pressure, a change in MPI allele frequencies would occur, yielding further reduction of $M P I^{120}$ abundance through generations. On the other hand, if the MPI polymorphism is to be maintained, a reversal of the selection on MPI allozymes has to take place: in this case, a counterselection on MPI allozymes possessing $M P I^{100}$ and $M P I^{110}$ should occur in embryos and/or young females in favour of $M P I^{120}$. The above-mentioned stability of

Table 3 Observed MPI allele frequencies in four subsamples of Lacerta vivipara at Paimpont, Brittany. See fig. 1

\begin{tabular}{|c|c|c|c|c|c|}
\hline & \multicolumn{2}{|l|}{ Males } & \multicolumn{3}{|l|}{ Females } \\
\hline & $M P I^{100}$ & $M P I^{120}$ & $M P I^{100}$ & $M P I^{110}$ & $M P I^{120}$ \\
\hline Subsample A & 18 & 8 & 3 & 4 & 1 \\
\hline Subsample B & 11 & 1 & 4 & 3 & 1 \\
\hline Subsample C & 7 & 3 & 2 & 2 & 0 \\
\hline Subsample D & 12 & 0 & 1 & 1 & 0 \\
\hline
\end{tabular}


Table 4 Absolute MPI allozyme frequencies observed in Common Lizard samples from Southern France's central mountains. From north to south

\begin{tabular}{|c|c|c|c|c|c|c|}
\hline \multirow[b]{2}{*}{ Origin } & \multicolumn{3}{|c|}{ Young females } & \multicolumn{3}{|c|}{ Adult females } \\
\hline & $\mathrm{MPI}^{100}$ & $\mathrm{MPI}^{110}$ & $\mathrm{MPI}^{120}$ & $\mathrm{MPI}^{100}$ & $\mathrm{MPI}^{110}$ & $\mathrm{MPI}^{120}$ \\
\hline Les Puys & - & - & - & 22 & 20 & 2 \\
\hline Lac de Charpal & 7 & 8 & 3 & 15 & 16 & 3 \\
\hline Mont Lozère & 20 & 22 & 6 & 36 & 38 & 2 \\
\hline Espinouse & 1 & 2 & 1 & 11 & 10 & 1 \\
\hline Total & 28 & 32 & 10 & 84 & 84 & 8 \\
\hline
\end{tabular}

genotype distribution observed in the Mount Lozère population through a few generations is in accordance with the existence of this endocyclic selection in L. vivipara. Note that endocyclic selection (method VIII-detected selection of Endler, 1986), implying exact balance of selective forces, is of common record in animals generally (Endler, 1986: 129ff) and reptiles in particular (Pasteur, 1977; Pasteur et al., 1988a).

As allele $M P I^{120}$ is present in both sex chromosomes (see table 2), endocyclic selection could act in two possible ways. The first implies selection occurring simultaneously on $M P I^{120}$ from both heterochromosomes. The second way would involve selection operating independently on the W chromosome or the MPI-bearing $\mathrm{Z}$ chromosome. At present we do not have sufficient data to elucidate the mechanism at play: absolute $M P I^{120}$ frequencies on $\mathrm{Z}$ and $\mathrm{W}$ chromosomes are too small to reveal differences between their distributions on male and female Zs or between Zs and Ws of different female age classes. Hundreds or maybe thousands of lizards would be needed to discriminate the right hypothesis.

\section{Geographic variation of MPI polymorphism}

Table 2 of regional allele frequencies at the Common Lizard MPI locus shows at a glance that (1) the five samples from France are notably homogeneous in genic composition, and so are the two from Germany, (2) French allele frequencies are found again in the Russian sample (compare expected genotype frequencies within each sex in table 1), and (3) German populations have apparently fixed the commonest alleles, i.e., $M P I^{100}$ on the $\mathrm{Zs}$ and $M P I^{110}$ on the Ws, while the lizards from Austria show definite fixation, on their W chromosome, of $M P I^{120}$ which is rare or absent elsewhere $(P<0 \cdot 001$ in all statistical comparisons with other samples).

\section{DISCUSSION}

If MPI alleles are sensitive to natural selection, then the question is raised whether the MPI locus can have contributed to setting up the sex-determination system of $L$. vivipara. It has been demonstrated that; when an autosome carrying a selected locus undergoes a translocation with a sex chromosome, the translocation success depends on selective values at the selected locus: for the resulting fusion to spread to fixation, all that is needed is a sex difference maintained between allele frequencies at this locus; and $\mathrm{W}$-autosome fusions are likely to be much more effective than $\mathrm{Z}$-autosome fusions on several grounds (Charlesworth and Charlesworth, 1980). Recall that the Common Lizard has a $\mathrm{Z}_{1} \mathrm{Z}_{2} \mathrm{~W}$ multiple chromosome system of a kind overlooked in White's $(1957,1973)$ classical account. It results from the centric fusion of a telocentric $\mathrm{W}$ chromosome with a telocentric autosome carrying the gene for MPI. The outcome was a large metacentric neo-W, one arm of which was homologous to the ancestral Z (homomorphic with the ancestral $W$ ), the other arm being homologous to the remaining autosome of the pair carrying the MPI locus. Pairs 11 and 15 of the $L$. vivipara karyotype were involved (Chevalier et al., 1979), but which one bore the enzyme locus is a question whose answer will have to wait until the gene controlling mannose-phosphate-isomerase synthesis is probed.

Since no exceptional phenotypes-such as a 110-carrying male or a $100 / 100$ female-are observed among the 309 of table 1, crossing over must be absent or virtually so between that locus and the sex factor (due to one or more inversions and/or to both being near the centromere). With the enormous numbers of $L$. vivipara, a very low rate of recombination would be sufficient to keep in polymorphic condition allele 110 in $\mathrm{Z}$ chromosomes and the male sex, as well as allele 100 in W chromosomes. That this does not obtain means the 
neo- $\mathrm{W}$ is fixed in all the populations sampled in the present study.

This study has raised the possibility that the MPI alleles can withstand sharp diversifying selection in the face of intense gene flow. Endler (1973) has shown that a 40 per cent migration rate between adjacent demes, in a cline maintained by selection where the selection increment is only 0.04 from every deme to the next, makes no difference, compared with no migration at all, to the outcome of selection. Therefore, the microgeographic habitat diversification suggested by the Paimpont observations above is theoretically sound, if in need of substantiation. On the other hand, the existence of endocyclic selection at the MPI locus has been vindicated.

In spite of this evidence, however, it seems that the MPI gene has played no role in the fixation of the neo-W chromosome. For one thing, according to the Charlesworths' (1980) results complete crossover suppression implies fixation in W chromosomes, and elimination from $\mathrm{Z}$ chromosomes, of the allele favoured in females relatively to males. Since at the locus under scrutiny, allele 120 is present in comparable proportions in both $\mathrm{W}$ and $\mathrm{Z}$ chromosome subpopulations (table 2), this allele can thus hardly have been relevant in the fixation process. Secondly, its constant frequency of about 10 per cent throughout France samples in both $\mathrm{Z}$ and $\mathrm{W}$ chromosomes indicates a balanced polymorphism in which $M P I^{100}$ and $M P I^{120}$ keep the same selective value irrespective of environmental variation. For this reason, they should not be relevant to the fixation process either. Thirdly, the ecological characteristics of the sampled German and Austrian biotopes being closely similar to those in the Massif Central, the haphazard-looking fixation of alleles observed in these two countries seems most likely to be due to past stochastic events rather than differing regional selective factors; the more so as the genetic composition observed in France is found again at the other end of the stretch of lands sampled.

The picture could be explained if there existed geographical variation among MPI alleles prior to the translocation, and if the fusion occurred in many places, being favoured thanks to different MPI alleles in different places. However, this hypothesis still admits the MPI gene as the key instrument in the fixation, in contradiction with the above comments. A more satisfactory hypothesis to explain the geographical pattern is that the fusion appeared only once, as is usually assumed for chromosomal mutations, that its propagation is due to another sex-linked gene sensitive to selection, and that after the translocation different inversions occurred in different places, as is observed in species where polytene chromosomes allow us to visualize inversions. Different inversions in different regions imply different positions of the MPI gene with respect to the acting gene and the sex factor, accounting for the observed geographical variation.

In terms of sex-chromosome gene evolution (see Charlesworth, 1978), the neo-W chromosome of $L$. vivipara looks quite recent, since it carries two functional alleles of a structural gene rather than being inert at the locus. In terms of chromosomal rearrangements, however, the final hypothesis above implies that quite a large amount of chromosomal evolution has taken place in Europe since the fusion appeared. The suspicion then arises that the fused chromosome may be fixed everywhere in the species, in which case the initial observations of homomorphic karyotypes would be erroneous and due to inadequate cytological techniques.

In conclusion, within the scope of realistic endeavours (searching for the second selected locus does not seem to be so at the present time), the present report warrants at least three kinds of further studies on the Common Lizard: firstly, verifying MPI habitat selection at Paimpont; secondly, investigating MPI genetic status in intermediate regions between those sampled here; thirdly, cytogenical survey, with at least three questions: (1) Has any heterochromatin developed in the metacentric $W$ that would have no homologue in the telocentric $\mathrm{Zs}$, indicating the start of inactivation? (2) Are different sets of inversions detected in the $\mathrm{W}$ chromosome thanks to modern marking techniques? (3) Are there any populations at all of this lizard which have homomorphic karyotypes, and if so are there any with polymorphism of the translocation?

Acknowledgements We are glad to thank Deborah Charlesworth for careful reading of the manuscript and efficient annotations, as well as Deborah and Brian Charlesworth for general advice. The 1986 material from Mount Lozère, France, was collected by Sacha Haywood, who participated in electrophoretic investigations of it. We are indebted to Werner Mayer for collecting and supplying the sample from Austria.

\section{REFERENCES}

BRINK, J. M. VAN 1959. L'expression morphologique de la digamétie chez les Sauropsidés et les Monotrèmes. Chromosoma, 10, 1-72. 
CHARLESWORTH, B. 1978. Model for evolution of Y chromosomes and dosage compensation. Proc. Natl Acad. Sci. USA, 75, 5618-5622.

CHARLESWORTH, D. AND CHARLESWORTH, B. 1980. Sex differences in fitness and selection for centric fusions between sex-chromosomes and autosomes. Genet. Res., 35 , 205-214.

Chevalier, M., Dufaure, J. P. AND LÉCher, P. 1979. Cytogenetic study of several species of Lacerta (Lacertidae, Reptilia) with particular reference to sex chromosomes. Genetica, 50, 11-18.

DELY, O. G. AND BÖHME, W. 1984. Lacerta vivipara Jacquin 1787-Bergeidechse. In Böhme, W. (ed.) Handbuch der Reptilien und Amphibien Europas, Aula, Wiesbaden, pp. 362-393.

ENDLER, J. A. 1973. Gene flow and population differentiation. Science, 179, 243-250.

ENDler, J. A. 1986. Natural Selection in the Wild. Princeton University Press, Princeton.

GOUX, J. M. AND PASTEUR, G. 1986. A sex-linked enzyme in a reptile-association with a recent centric fusion in the common lizard. Genet. Res., 48, 21-25.
HeUlin, B. 1984. Contribution à l'étude de la biologie des populations de Lacerta vivipara. Doctorate thesis, University of Rennes.

ORLOVA, V. F. AND ORLOV, N. F. 1969. Chromosome complements and some questions of systematics of lizards of the genus Lacerta. Zool. Zh., 48, 1056-1060.

PASTeur, G. 1977. Endocyclic selection in reptiles. Amer. Nat., $111,1027-1030$.

PASTEUR, G., KEYMAR, P. F. AND PERRET, J. L. 1988 a. Canarian Skink Systematics: An Introduction. Ecole Pratique des Hautes Etudes, Montpellier.

PASTEUR, N., PASTEUR, G., BONHOMME, F., CATALAN, J. AND BRITTON-DAVIDIAN, J. 1988 b. Practical Isozyme Genetics. Ellis Horwood/John Wiley, Chichester.

PILORGE, T. 1981. Stratégie adaptative d'une population de montagne de Lacerta vivipara. Oikos, 39, 206-212.

WHITE, M. J. D. 1957. Some general problems of chromosomal evolution and speciation in animals. In Glass, B. (ed.) Survey of Biological Progress 3, 109-147.

White, M. J. D. 1973. Animal Cytology and Evolution. Cambridge University Press, Cambridge. 